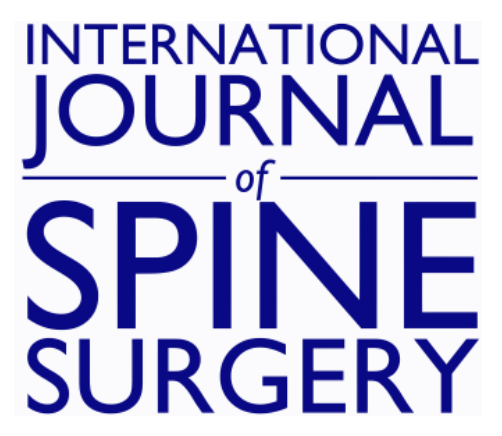

\title{
Complications After Adult Spinal Deformity Surgeries: All Are Not Created Equal
}

Michael Dinizo, Igor Dolgalev, Peter G. Passias, Thomas J. Errico and Tina Raman

Int J Spine Surg 2021, 15 (1) 137-143

doi: https://doi.org/10.14444/8018

http://ijssurgery.com/content/15/1/137

This information is current as of April 26, 2023.

Email Alerts Receive free email-alerts when new articles cite this article. Sign up at:

http://ijssurgery.com/alerts

The International Journal of Spine Surgery

2397 Waterbury Circle, Suite 1,

Aurora, IL 60504, Phone: +1-630-375-1432 


\title{
Complications After Adult Spinal Deformity Surgeries: All Are Not Created Equal
}

\author{
MICHAEL DINIZO, MD,${ }^{1}$ IGOR DOLGALEV, MS, ${ }^{1}$ PETER G. PASSIAS, MD,${ }^{1}$ THOMAS J. ERRICO, MD ${ }^{2}$ \\ TINA RAMAN, MD ${ }^{1}$ \\ ${ }^{I}$ Department of Orthopaedic Surgery, NYU Langone Orthopedic Hospital, New York, New York, ${ }^{2}$ Nicklaus Childrens Hospital, Miami, Florida
}

\begin{abstract}
Background: Data on timing of complications are important for accurate quality assessments. We sought to better define pre- and postdischarge complications occurring within 90 days of adult spinal deformity (ASD) surgery and quantify the effect of multiple complications on recovery.

Methods: We performed a review of 1040 patients who underwent ASD surgery (age: $46 \pm 23$; body mass index: $25 \pm 7$, American Society of Anesthesiologists [ASA] score: $2.5 \pm 0.6$, levels: $10 \pm 4$, revision: 9\%, 3-column osteotomy: 13\%). We assessed pre- and postdischarge complications and risk factors for isolated versus multiple complications, as well as the impact of multiple complications.

Results: The 90-day complication rate was $17.7 \%$. 85 patients $(8.2 \%)$ developed a predischarge complication, most commonly ileus (12\%), and pulmonary embolism (PE; 7.1\%). The most common causes of predischarge unplanned reoperation were neurologic injury (12.9\%) and surgical site drainage $(8.2 \%)$. Predictors of a predischarge complication included smoking (odds ratio [OR]: 2.2, $P=.02$ ), higher ASA (OR: 1.8, $P=.008$ ), hypertension (HTN; OR: $2.0, P=.004)$, and iliac fixation (OR: $4.3, P<.001)$. Ninety-nine patients $(9.5 \%)$ developed a postdischarge complication, most commonly infection (34\%), instrumentation failure (13.4\%), and proximal junctional failure $(10.4 \%)$. Predictors of postdischarge complications included chronic obstructive pulmonary disease (OR: $3.6, P<$ $.0001)$, congestive heart failure (OR: 4.4, $P=.016)$, HTN (OR: $2.3, P<.0001)$, and multiple rod construct $(\mathrm{OR}: 1.8, P=$ $.02)$. Patients who developed multiple complications $(9.3 \%)$ had a longer length of stay, and increased risk for readmission and unplanned reoperation.

Conclusions: Knowledge regarding timing of postoperative complications in relation to discharge may better inform quality improvement measures. PE and implant-related complications play a prominent role in perioperative complications and need for readmission, with several modifiable risk factors identified.

Level of Evidence: Level 3.

Clinical Relevance: Advances in surgical techniques and instrumentation have improved postoperative radiographic and clinical outcomes after ASD surgery. The rate of complications after complex ASD surgery remains high, both at early postoperative and long term follow-up. This study reviews complications within 90 days of surgery, with an assessment of patient and surgical risk factors. We found that modifiable risk factors for early complications after ASD surgery include COPD, and current smoking. The data presented in this study also provide surgeons with knowledge of the most common complications encountered after ASD surgery, to aid in preoperative patient discussion.
\end{abstract}

Complications

Keywords: complications, adult spinal deformity, quality improvement

\section{INTRODUCTION}

Adult spinal deformity (ASD) surgeries are inherently complex procedures, and often entail multiple osteotomies, combined anterior/posterior approaches, and long fusions, all of which can confer substantially increased risk for complications and reoperation after index surgery. There is now a vast body of literature investigating and describing complications after ASD surgery with most reports identifying a perioperative complication rate of approximately $13 \%-41 \%{ }^{1,2}$ In one of the larger studies to date, the rate of medical complications within 6 weeks of ASD surgery was found to be $26.8 \%$. $^{3}$ Within 30 days of ASD surgery, the rate of unplanned return to the operating room is reportedly $2.8 \%$, and $24 \%$ at 2 -year follow-up. ${ }^{4-6}$ Previous studies have identified advanced age, smoking, and osteoporosis as important contributors to risk for perioperative complications. ${ }^{7,8}$ Surgical factors including fusion of greater than 13 levels, longer operative times, and blood loss are also associated 
with an increased risk for complications and unplanned reoperation and readmission. ${ }^{9-11}$

Readmission after surgical procedures is common and can affect between $3 \%$ and $25 \%$ of patients postoperatively. ${ }^{12,13}$ Patients considering surgical interventions are concerned with functional and cognitive outcomes after surgery. Readmission to the hospital and unplanned reoperations represent major events for patients and have considerable impacts on all healthcare stakeholders, particularly when the reoperations occur within 90 days of the initial surgery. ${ }^{14}$ Complications have a demonstrated association with increased burden on the healthcare system, resulting in increased resource utilization, longer hospital stay, and higher costs. ${ }^{15}$ For this reason, complication rate has been used as a criterion for evaluating surgical department practice and even overall hospital care. ${ }^{16}$ A major medical complication can sometimes entail prolonged immobilization, or inability to participate in physical therapy, leading to subsequent complications such as delayed wound healing or wound dehiscence from prolonged bed rest. Although even an isolated complication can deter the overall postoperative recovery, we hypothesize that the effect of some complications is greater than others, and that the effect of concomitant complications is substantially greater. To date, there are few studies that have examined the effect of multiple complications on patient recovery from a large singleinstitution database. In this regard, we sought to define the most frequent pre- and postdischarge complications occurring within 90 days of ASD surgery using a large single-center database, and define the effects of these complications on readmission, need for unplanned reoperation, and prolonged length of stay.

\section{MATERIALS AND METHODS}

We retrospectively reviewed our institution's prospectively collected database to identify patients who were aged 18 years or older when they underwent posterior spinal fusion for ASD, with a minimum of 4 levels fused, from January 2012 through December 2017. We identified 1040 such patients with complete surgical and inpatient admission data.

\section{Patient and Surgical Characteristics}

The primary indications for surgery were scoliosis or kyphosis with pain and disability for which prolonged nonoperative treatment had failed. Of the 1040 patients, 90 were patients who had undergone previous spinal surgery $(8.8 \%)$. We used the clinical database and patients' medical records to ascertain patient characteristics including age, sex, and American Society of Anesthesiologists (ASA) score. Based on a validated 5-item frailty index, a modified frailty index (mFI) was calculated for each patient, with 5 categories of frailty ranging from 1 (lowest) to 5 (highest).

Surgical parameters collected included number of levels fused, the use of pelvic fixation, interbody fusion, and multi-rod construct. Each case was assigned a Mirza invasiveness index, based on published criteria, for the purposes of assessing surgical complexity between the 2 groups.

\section{Complications and Unplanned Reoperations}

Our primary outcome of interest was complications incurred within 90 days of the index surgery. All major and minor complications, as outlined by Glassman et al, ${ }^{1}$ were included in this analysis. Complications related to technical details of surgery were categorized retrospectively by one attending spine surgeon, the senior author on the study, through review of operative reports and relevant imaging. Subanalysis was conducted to compare predictors of isolated versus multiple complications, as well as the types of complications that imparted the greatest risk for readmission and unplanned return to the operating room. All clinical information was abstracted from our electronic medical records.

\section{Statistical Analysis}

Univariable regression analyses were used to determine the unadjusted effect of preoperative patient risk factors and operative variables on our primary and secondary outcomes. Covariates associated with a defined outcome, here denoted by a $P$ value of less than .20, were included in multivariable logistic regression models. Akaike information criteria, likelihood ratios, and Hosmer-Lemeshow goodness-of-fit tests were used at the addition of each potential covariate to select the most parsimonious model for each outcome.

Complications were separated into isolated (ie, a single complication) and combined complications, depending on whether the individual complication was experienced in isolation or in addition to another complication during the postoperative 
Table 1. Baseline characteristics for 1040 adults separated by number of complications.

\begin{tabular}{|c|c|c|c|c|c|}
\hline Preoperative Characteristic & $\begin{array}{c}\text { Multiple } \\
\text { Complications } \\
(\mathrm{n}=97)\end{array}$ & $\begin{array}{c}\text { No } \\
\text { Complication } \\
(\mathrm{n}=\mathbf{8 1 5})\end{array}$ & $\begin{array}{c}P \text { Value } \\
\text { (Multiple Versus } \\
\text { No Complications) }\end{array}$ & $\begin{array}{c}\text { Isolated } \\
\text { Complication } \\
(\mathrm{n}=128)\end{array}$ & $\begin{array}{c}P \text { Value (Multiple Versus } \\
\text { Isolated Complications) }\end{array}$ \\
\hline Age, $y^{a}$ & $60 \pm 15^{\mathrm{a}}$ & $43 \pm 24$ & $<.0001$ & $56 \pm 20$ & .39 \\
\hline $\mathrm{BMI}^{\mathrm{a}}$ & $27 \pm 7$ & $25 \pm 6$ & .019 & $28 \pm 8$ & .98 \\
\hline ASA score ${ }^{a}$ & $2.5 \pm 0.5$ & $2.4 \pm 0.7$ & .83 & $2.5 \pm 0.5$ & .96 \\
\hline $\mathrm{mFI}^{\mathrm{a}}$ & $0.67 \pm 0.72$ & $0.37 \pm 0.65$ & $<.0001$ & $0.71 \pm 0.87$ & .95 \\
\hline Diabetes mellitus ${ }^{\mathrm{b}}$ & $9(9.3)$ & $63(7.7)$ & .59 & $17(13.3)$ & .35 \\
\hline $\mathrm{COPD}^{\mathrm{b}}$ & $10(10.3)$ & $27(3.3)$ & .001 & $14(10.9)$ & .88 \\
\hline Hypertension ${ }^{\mathrm{b}}$ & $45(46)$ & $197(24)$ & $<.0001$ & $55(43)$ & .61 \\
\hline Smoker ${ }^{\mathrm{b}}$ & $13(13)$ & $52(6.4)$ & .011 & $14(11)$ & .57 \\
\hline Revision surgery ${ }^{\mathrm{b}}$ & $13(13)$ & $61(7.5)$ & .044 & $18(14)$ & .89 \\
\hline
\end{tabular}

Abbreviations: ASA, American Society of Anesthesiologists; BMI, body mass index; COPD, chronic obstructive pulmonary disorder; mFI, modified frailty index ${ }^{\mathrm{a}}$ Expressed as mean $\pm \mathrm{SD}$.

${ }^{\mathrm{b}}$ Expressed as n (\%).

hospitalization. Complication combinations with a sample size of fewer than 5 patients were excluded from analysis in the regression model.

Groups were compared with the $t$ test statistic or Mann-Whitney nonparametric statistic for continuous parameters. Chi-square tests were used for categorical data when all the expected counts had 5 or more observations, and Fisher exact tests were used for categorical data when any of the expected counts had fewer than 5 observations.

Descriptive statistics were calculated with SPSS version 25 software (IBM, Armonk, New York), R statistical software, and Microsoft Office Excel software (Microsoft Corp, Redmond, Washington).

\section{RESULTS}

\section{Patient Population}

Included in the study were 1040 adults (703 women, 67.8\%) who underwent surgery for ASD. Among this group, 1 complication occurred in 242 patients $(23.3 \%)$, and multiple complications occurred in 97 patients $(9.3 \%)$ : 63 patients $(6.1 \%)$ with 2 complications, 15 patients $(1.4 \%)$ with 3 complications, and 19 patients $(1.8 \%)$ with more than 3 complications.

\section{Pre- and Postdischarge Complications}

Eighty-five patients $(8.2 \%)$ developed a predischarge complication, of which $20 \% \quad(n=17)$ required reoperation. The most common predischarge medical complications were ileus $(12 \%, \mathrm{n}=$ $10)$ and pulmonary embolism $(7.1 \%, n=6)$. For the 85 patients who sustained a predischarge complication, the most common causes of predischarge unplanned return to the operating room were neurologic injury $(12.9 \%, \mathrm{n}=11)$, surgical site drainage $(8.2 \%, \mathrm{n}=7)$, and proximal junctional failure $(4.7 \%, \mathrm{n}=4)$. Ninety-nine patients $(9.4 \%)$ developed a postdischarge complication, of which $73(7 \%)$ required readmission for unplanned reoperation $(92 \%, n=67)$ or management $(8.2 \%, n=6)$. Of the 99 patients, the most common postdischarge medical complications were pneumonia $(5.0 \%, \mathrm{n}=$ 5), pulmonary embolism $(4.0 \%, \mathrm{n}=4)$, and deep vein thrombosis (DVT; 3.0\%, $\mathrm{n}=3$ ). For the 67 patients who required unplanned return to the operating room postdischarge, the most common causes were infection $(34 \%, \mathrm{n}=23)$, neurologic injury $(23.9 \%, \mathrm{n}=16)$, instrumentation failure including malpositioned pedicle screw or interbody cage migration $(13.4 \%, \mathrm{n}=9)$, and proximal junctional failure $(10.4 \%, \mathrm{n}=7)$.

\section{Isolated Versus Multiple Complications}

ASD patients who experienced multiple complications $(n=97,9.3 \%)$ postoperatively revealed substantial differences in preoperative characteristics compared with those who recovered without complications $(\mathrm{n}=815,78.3 \%)$ or those with an isolated complication $(\mathrm{n}=128,12.3 \%)$ (Table 1$)$. Patients who suffered multiple complications were more commonly older, had a higher body mass index, and a higher modified frailty score. They more commonly had undergone a revision surgery, and more commonly had comorbidities including chronic obstructive pulmonary disease (COPD) and cardiovascular disease, and were smokers. ASD patients who experienced multiple complications postoperatively also revealed substantial differences in intraoperative details, compared with those who recovered without complications or with an isolated complication (Table 2). Surgeries that were associated with multiple postoperative complications had 
Table 2. Surgical characteristics for 1040 adults separated by number of complications.

\begin{tabular}{|c|c|c|c|c|c|}
\hline Characteristic & $\begin{array}{c}\text { Multiple } \\
\text { Complication } \\
(\mathbf{n}=97) \\
\end{array}$ & $\begin{array}{c}\text { No } \\
\text { Complication } \\
(\mathrm{n}=\mathbf{8 1 5}) \\
\end{array}$ & $\begin{array}{c}P \text { Value } \\
\text { (Multiple Versus } \\
\text { No Complications) } \\
\end{array}$ & $\begin{array}{c}\text { Isolated } \\
\text { Complication } \\
(\mathrm{n}=128) \\
\end{array}$ & $\begin{array}{l}P \text { Value (Multiple Versus } \\
\text { Isolated Complications) }\end{array}$ \\
\hline \multicolumn{6}{|l|}{ Preoperative } \\
\hline Levels $^{\mathrm{a}}$ & $12 \pm 5$ & $10 \pm 4$ & $<.0001$ & $11 \pm 4$ & .42 \\
\hline Pelvic fixation ${ }^{b}$ & $59(61)$ & $236(29)$ & $<.001$ & $65(51)$ & .23 \\
\hline $\mathrm{PSO}^{\mathrm{b}}$ & $26(27)$ & $82(10)$ & $<.001$ & $30(23)$ & .56 \\
\hline Interbody $^{\mathrm{b}}$ & $50(52)$ & $230(28)$ & $<.0001$ & $57(45)$ & .28 \\
\hline Multiple-rod configuration ${ }^{\mathrm{b}}$ & $20(21)$ & $108(13)$ & .048 & $29(23)$ & .74 \\
\hline Operative time $^{\mathrm{a}}$ & $467 \pm 211$ & $389 \pm 210$ & .001 & $443 \pm 147$ & .95 \\
\hline Estimated blood loss ${ }^{\mathrm{a}}$ & $2358 \pm 2015$ & $1470 \pm 1338$ & $<.0001$ & $2147 \pm 1800$ & .88 \\
\hline Intraoperative $\mathrm{RBCs}$ transfused $(\mathrm{U})^{\mathrm{a}}$ & $2.5 \pm 2.4$ & $0.96 \pm 1.8$ & $<.0001$ & $1.9 \pm 2.2$ & .06 \\
\hline
\end{tabular}

Abbreviations: PSO, pedicle subtraction osteotomy; RBC, red blood cell.

${ }^{\mathrm{a}}$ Expressed as mean $\pm \mathrm{SD}$.

${ }^{\mathrm{b}}$ Expressed as n (\%).

a greater number of levels fused, and 3-column osteotomy (3CO), interbody, and pelvic fixation procedures performed, and use of a multiple-rod construct. Surgeries that were associated with multiple postoperative complications demonstrated a longer operative time, higher estimated blood loss, and greater number of intraoperative packed red blood cells (pRBCs) transfused.

Multiple patient characteristics including current smoking status, COPD, hypertension, history of DVT, and a higher mFI score were independently associated with increased risk for sustaining multiple complications (Table 3). Surgical characteristics including undergoing $3 \mathrm{CO}$, pelvic fixation, or interbody fusion; having an increased volume of pRBCs transfused intraoperatively; and undergoing a multiple-rod construct were independently associated with increased risk for sustaining multiple complications (Table 4).

\section{Impact on Readmission and Unplanned Return to the Operating Room}

Seventy-three patients $(7.0 \%)$ required readmission to the hospital for unplanned return to the operating room or management of medical and surgical complications. Of the patients who developed multiple complications, 44/97 (45\%) required readmission to the hospital for further investigation

Table 3. Patient characteristics associated with development of multiple complications after adult spinal deformity surgery.

\begin{tabular}{lcc}
\hline Parameter & Odds Ratio (95\% CI) & $P$ Value \\
\hline Current Smoker & $2.1(1.05-3.8)$ & .03 \\
COPD & $2.5(1.2-5.0)$ & .01 \\
Hypertension & $2.4(1.5-3.6)$ & $<.0001$ \\
mFI & $1.5(1.2-2.0)$ & .001 \\
\hline
\end{tabular}

Abbreviations: CI, confidence interval; COPD, chronic obstructive pulmonary disorder; mFI, modified frailty index. and observation, and 54/97 (56\%) required unplanned reoperation. Of patients who developed only 1 complication, $26 / 128(20 \%)$ required readmission to the hospital, and $27 / 128(21 \%)$ required unplanned reoperation.

By regression analysis, there were no medical complications that were independently associated with increased risk for readmission within 90 days. Physical exam documentation during the index inpatient stay of a new postoperative motor or sensory deficit was independently associated with increased risk for readmission to the hospital within 90 days of surgery (odds ratio [OR]: 15.4, 95\% confidence interval: 6.4-37.4).

\section{Impact on Length of Stay}

The mean \pm SD length of stay at index hospitalization in patients who did not incur any complication was $5.9 \pm 3.0$ days, while the length of stay for patients who incurred a single complication was 8.9 \pm 7.5 days, and that for patients with multiple complications was $9.6 \pm 6.8$ days. The difference in length of stay between patients with no complications versus those with an isolated or multiple complications was significantly different $(P<.0001)$.

\section{DISCUSSION}

In the present study, we found that $9.3 \%$ of ASD patients experienced multiple major postoperative

Table 4. Surgical characteristics associated with development of multiple complications after adult spinal deformity surgery.

\begin{tabular}{lcc}
\hline Parameter & Odds Ratio $\mathbf{( 9 5 \% ~ C I ) ~}$ & $\boldsymbol{P}$ Value \\
\hline Pelvic fixation & $2.3(1.6-3.3)$ & $<.0001$ \\
3 CO & $2.7(1.6-4.4)$ & $<.0001$ \\
Interbody fusion & $2.5(1.7-3.9)$ & $<.0001$ \\
Intraoperative pRBC transfusion & $3.7(2.4-5.9)$ & $<.0001$ \\
\hline
\end{tabular}

Abbreviations: 3CO, 3-column osteotomy; pRBC, packed red blood cells. 
complications, with an associated risk for readmission to the hospital of $45 \%$, and a risk for unplanned return to the operating room of $56 \%$. Patients who developed multiple complications experienced a significantly longer length of hospital stay and had a higher rate for readmission and reoperation compared with those who did not develop any complications. Predictors of sustaining multiple complications included current smoking, COPD, hypertension, history of DVT, higher mFI, and undergoing surgeries with increased complexity.

Postoperative complications and hospital readmissions within a short period after the initial surgery contribute significantly to overall healthcare costs and resource utilization. ${ }^{17}$ Complex ASD surgery is of particular interest in this regard, because it has relatively high readmission and reoperation rates compared with other surgeries. A study of 718 ASD patients with greater than 2-year follow-up demonstrated a $17.9 \%$ reoperation and $17.7 \%$ readmission rate. ${ }^{18}$ Similar analyses among ASD surgical populations have demonstrated an inverse relationship between number of complications incurred after the operation and patient quality of life. ${ }^{19-21}$ Despite some discrepancies between complications defined by investigators in those studies, as well as differences in methodology and patient sample among studies, the principle remains the same. Major postoperative complications are associated with increased length of stay, increased need for subsequent procedures, and worse health-related quality of life scores. ${ }^{22}$

We found that risk factors for the development of multiple complications included patient characteristics such as current smoking status, COPD, hypertension, history of DVT, and a higher mFI score. The strong association between these factors and development of a complication after ASD surgery is consistent with the findings of previous studies. $^{23-25}$ A few studies have reported that diabetes and smoking are risk factors for infection and cardiopulmonary and other medical complications after ASD surgery., ${ }^{3,26}$ Interestingly, our findings that smoking is an independent risk factors for development of multiple complications after ASD surgery are different than those of De la Garza Ramos et $\mathrm{al}^{27}$ who found that smoking was not associated with a higher 30-day complication rate in a study utilizing the American College of Surgeons National Surgical Quality Improvement Program database. The difference in findings may be ex- plained by the longer perioperative follow-up in our study of 90 days, as well as the equivalent complexity of surgery that smokers and nonsmokers in the present study underwent, with no significant difference in number of levels fused (10 in both groups) or Mirza invasiveness index (20 in the nonsmoking group, 21 in the smoking group).

COPD is a described risk factor for increased 30day readmission after 1- or 2-level lumbar fusion. ${ }^{28}$ Karikari et $\mathrm{al}^{29}$ reported that patients with COPD had increased length of stay and higher rates of postoperative pneumonia after spine fusion surgery greater than 3 levels. Similarly, we found that COPD increased the risk of incurring multiple complications postoperatively in this large cohort. While the need to maintain adequate oxygen levels may require prolonged postoperative mechanical ventilation, we did not find any difference in this study in rates of prolonged ventilation postoperatively, or rate of unplanned reintubation, between patients who had COPD or those that did not.

Undergoing $3 \mathrm{CO}$ and receiving a higher volume of intraoperative $\mathrm{pRBCs}$ intraoperatively are known risk factors for complications after ASD surgery. ${ }^{26,30}$ We further found that undergoing pelvic fixation and interbody fusion conferred increased risk for undergoing multiple complications. Fusion to the pelvis and osteotomies routinely appear in studies on this topic, as predictors of complications and higher risk for infection. ${ }^{31-33}$ These are likely surrogates for increased complexity of a given case, and more research is needed to understand what proportion of risk is conferred by each of these components of the surgical plan.

We evaluated prolonged length of hospital stay as an outcome to better elucidate the incremental cost of care associated with multiple postoperative complications, because the literature supports a correlation between health care spending and hospital length of stay. ${ }^{34,35}$ Previous investigations have found that an increased number of intraoperative complications was associated with extended length of stay. ${ }^{34}$ Similar to these observations, postoperative hospital length of stay increased from 5.9 days for those with no complications to 8.9 days with an isolated complication and 9.6 days for those with 2 or more complications in our study. While most surgeons will agree that patient care be the first priority in determining the length of stay in the hospital, the financial impact of an extended length 
of hospital stay must be understood in the current healthcare climate. ${ }^{35}$

The strengths of this study are the relatively homogenous population of ASD patients with long fusion constructs and equivalent case complexity. The retrospective nature of our study could be perceived as a weakness; however, most data were collected prospectively. All patients were from a single institution and treated by surgeons who treat a large volume of adults with spinal deformity, which may limit the generalizability of our results. However, the exclusivity also conferred uniformity, and one might expect these types of surgical procedures to be performed at a tertiary care center by surgeons with similar experience.

This single-institution analysis is one of the first studies to demonstrate the impact of multiple major complications on readmission and revision after ASD surgery. Knowledge of preoperative and intraoperative risk factors for multiple complications will enable providers to better identify those at risk and individualize treatment strategies that afford patients the best chance of uncomplicated recovery. This will also improve prognostication and provide realistic expectations for families regarding expected length of stay and risk of requiring revision surgeries. This may ultimately also help reduce institutional variation in ASD complication rates and improve outcomes.

\section{REFERENCES}

1. Glassman SD, Hamill CL, Bridwell KH, Schwab FJ, Dimar JR, Lowe TG. The impact of perioperative complications on clinical outcome in adult deformity surgery. Spine. 2007;32(24):2764-2770. doi:10.1097/BRS.0b013e31815a7644

2. Núñez-Pereira S, Vila-Casademunt A, Domingo-Sàbat M, et al. Impact of early unanticipated revision surgery on healthrelated quality of life after adult spinal deformity surgery. Spine J. 2018;18(6):926-934. doi:10.1016/j.spinee.2017.09.017

3. Soroceanu A, Burton DC, Oren JH, et al. Medical complications after adult spinal deformity surgery: incidence, risk factors, and clinical impact. Spine. 2016;41(22):1718-1723. doi:10.1097/BRS.0000000000001636

4. Li Z, Shen J, Qiu G, et al. Unplanned reoperation within 30 days of fusion surgery for spinal deformity. PLOS ONE. 2014;9(3):e87172. doi:10.1371/journal.pone.0087172

5. Crawford CH, Glassman SD, Carreon LY, et al. Prevalence and indications for unplanned reoperations following index surgery in the adult symptomatic lumbar scoliosis NIH-sponsored clinical trial. Spine Deform. 2018;6(6):741-744. doi:10.1016/j.jspd.2018.04.006

6. Adogwa O, Elsamadicy AA, Han J, Karikari IO, Cheng J, Bagley CA. Drivers of 30-day readmission in elderly patients $(>65$ years old) after spine surgery: an analysis of 500 consecutive spine surgery patients. World Neurosurg. 2017;97:518-522. doi:10.1016/j.wneu.2016.07.032

7. Veeravagu A, Li A, Swinney C, et al. Predicting complication risk in spine surgery: a prospective analysis of a novel risk assessment tool. J Neurosurg Spine. 2017;27(1):81-91. doi:10.3171/2016.12.SPINE16969

8. Yoshida G, Hasegawa T, Yamato Y, et al. Predicting perioperative complications in adult spinal deformity surgery using a simple sliding scale. Spine. 2018;43(8):562-570. doi:10. 1097/BRS.0000000000002411

9. Aoude A, Nooh A, Fortin M, et al. Incidence, predictors, and postoperative complications of blood transfusion in thoracic and lumbar fusion surgery: an analysis of 13,695 patients from the American College of Surgeons National Surgical Quality Improvement Program database. Global Spine J. 2016;6(8):756-764. doi:10.1055/s-0036-1580736

10. Berenholtz SM, Pronovost PJ, Mullany D, et al. Predictors of transfusion for spinal surgery in Maryland, 1997 to 2000. Transfusion. 2002;42(2):183-189.

11. Elsamadicy AA, Adogwa O, Ongele M, et al. Preoperative hemoglobin level is associated with increased health care use after elective spinal fusion $(\geq 3$ levels) in elderly male patients with spine deformity. World Neurosurg. 2018;112:e348e354. doi:10.1016/j.wneu.2018.01.046

12. Camino Willhuber G, Elizondo C, Slullitel P. Analysis of postoperative complications in spinal surgery, hospital length of stay, and unplanned readmission: application of dindo-clavien classification to spine surgery. Global Spine J. 2019;9(3):279286. doi: $10.1177 / 2192568218792053$

13. Ramaswamy A, Marchese M, Cole AP, et al. Comparison of hospital readmission after total hip and total knee arthroplasty vs spinal surgery after implementation of the hospital readmissions reduction program. JAMA Netw Open. 2019;2(5):e194634. doi:10.1001/jamanetworkopen.2019.4634

14. Adogwa O, Elsamadicy AA, Han JL, Karikari IO, Cheng J, Bagley CA. 30-day readmission after spine surgery: an analysis of 1400 consecutive spine surgery patients. Spine. 2017;42(7):520-524. doi:10.1097/BRS.0000000000001779

15. Jacobs BL, He C, Li BY, et al. Variation in readmission expenditures after high-risk surgery. J Surg Res. 2017;213:6068. doi:10.1016/j.jss.2017.02.017

16. Mirza SK, Deyo RA, Heagerty PJ, Turner JA, Lee LA, Goodkin R. Towards standardized measurement of adverse events in spine surgery: conceptual model and pilot evaluation. BMC Musculoskelet Disord. 2006;7:53. doi:10.1186/1471-2474$7-53$

17. Dagal A, Bellabarba C, Bransford R, et al. Enhanced perioperative care for major spine surgery. Spine. 2019;44(13):959-966. doi:10.1097/BRS.0000000000002968

18. Pellisé F, Serra-Burriel M, Smith JS, et al. Development and validation of risk stratification models for adult spinal deformity surgery. J Neurosurg Spine. June 2019:1-13. doi:10. 3171/2019.3.SPINE181452

19. Hamilton DK, Carlson BB, Klineberg EO, et al. Patients incurring multiple complications following adult spinal deformity (ASD) surgery demonstrate an additive effect resulting in incremental worsening of health related quality of life (HRQOL). Spine J. 2015;15(10):S191-S192. doi:10.1016/j. spinee.2015.07.252

20. Yagi M, Michikawa T, Hosogane N, et al. Risk, recovery, and clinical impact of neurological complications in 
adult spinal deformity surgery. Spine. 2019;44(19):1364-1370. doi:10.1097/BRS.0000000000003080

21. Smith JS, Shaffrey CI, Lafage V, et al. Comparison of best versus worst clinical outcomes for adult spinal deformity surgery: a retrospective review of a prospectively collected, multicenter database with 2-year follow-up. J Neurosurg Spine. 2015;23(3):349-359. doi:10.3171/2014.12.SPINE14777

22. Blumberg TJ, Woelber E, Bellabarba C, Bransford R, Spina N. Predictors of increased cost and length of stay in the treatment of postoperative spine surgical site infection. Spine J. 2018;18(2):300-306. doi:10.1016/j.spinee.2017.07.173

23. Thomas K, Wong KH, Steelman SC, Rodriguez A. Surgical risk assessment and prevention in elderly spinal deformity patients. Geriatr Orthop Surg Rehabil. 2019;10:2151459319851681. doi:10.1177/2151459319851681

24. Sethi R, Buchlak QD, Yanamadala V, et al. A systematic multidisciplinary initiative for reducing the risk of complications in adult scoliosis surgery. $J$ Neurosurg Spine. 2017;26(6):744-750. doi:10.3171/2016.11.SPINE16537

25. Drazin D, Shirzadi A, Rosner J, et al. Complications and outcomes after spinal deformity surgery in the elderly: review of the existing literature and future directions. Neurosurg Focus. 2011;31(4):E3. doi:10.3171/2011.7.FOCUS11145

26. Zhang X-N, Sun X-Y, Hai Y, Meng X-L, Wang Y-S. Incidence and risk factors for multiple medical complications in adult degenerative scoliosis long-level fusion. J Clin Neurosci. 2018;54:14-19. doi:10.1016/j.jocn.2018.04.070

27. De la Garza Ramos R, Goodwin CR, Qadi M, et al. Impact of smoking on 30-day morbidity and mortality in adult spinal deformity surgery. Spine. 2017;42(7):465-470. doi:10. 1097/BRS.0000000000001795

28. Malik AT, Jain N, Kim J, Khan SN, Yu E. Chronic obstructive pulmonary disease is an independent predictor for 30-day readmissions following 1- to 2-level posterior lumbar fusions. J Spine Surg. 2018;4(3):553-559. doi:10.21037/jss.2018. 07.03

29. Elsamadicy AA, Sergesketter AR, Kemeny H, et al. Impact of chronic obstructive pulmonary disease on postoperative complication rates, ambulation, and length of hospital stay after elective spinal fusion ( $\geq 3$ levels) in elderly spine deformity patients. World Neurosurg. 2018;116:e1122-e1128. doi:10.1016/j.wneu.2018.05.185

30. Passias PG, Poorman GW, Bortz CA, et al. Predictors of adverse discharge disposition in adult spinal deformity and associated costs. Spine J. 2018;18(10):1845-1852. doi:10.1016/j. spinee.2018.03.022

31. Daniels AH, Reid DBC, Tran SN, et al. Evolution in surgical approach, complications, and outcomes in an adult spinal deformity surgery multicenter study group patient population. Spine Deform. 2019;7(3):481-488. doi:10.1016/j. jspd.2018.09.013

32. Elder BD, Ishida W, Lo S-FL, et al. Use of S2-alar-iliac screws associated with less complications than iliac screws in adult lumbosacropelvic fixation. Spine. 2017;42(3):E142-E149. doi:10.1097/BRS.0000000000001722

33. Liu G, Hasan MY, Wong H-K. Subcrestal iliac-screw: a technical note describing a free hand, in-line, low profile iliac screw insertion technique to avoid side-connector use and reduce implant complications. Spine. 2018;43(2):E68-E74. doi:10.1097/BRS.0000000000002239

34. Klineberg EO, Passias PG, Jalai CM, et al. Predicting extended length of hospital stay in an adult spinal deformity surgical population. Spine. 2016;41(13):E798-805. doi:10.1097/ BRS.0000000000001391

35. Nunley PD, Mundis GM, Fessler RG, et al. Impact of case type, length of stay, institution type, and comorbidities on Medicare diagnosis-related group reimbursement for adult spinal deformity surgery. Neurosurgical Focus. 2017;43(6):E11. doi:10.3171/2017.7.FOCUS17278

Disclosures and COI: The authors did not receive any funding or grants in support of their research for or preparation of this work.

Corresponding Author: Tina Raman, MD, NYU Langone Orthopedic Hospital, 171 Delancey Street, New York, NY 10003. Phone: (212) 5986000; Email: tina.raman@nyulangone.org.

Published 26 February 2021

This manuscript is generously published free of charge by ISASS, the International Society for the Advancement of Spine Surgery. Copyright (C) 2021 ISASS. To see more or order reprints or permissions, see http://ijssurgery.com. 